\title{
Analysis of Crown Inclination and Influencing Factors of Cunninghamia Lanceolata in Huangfengqiao, Hunan Province
}

\author{
Y.C. Zhang, H.Q. Zhang, Y.F. Chen \\ Research Institute of Forest Resource Information Techniques \\ Chinese Academy of Forestry \\ China
}

\begin{abstract}
Research object was middle-aged plantation of Cunninghamia Lanceolata in Huangfengqiao national forest farm, You county, Hunan Province. Ratio of crown inclination (RCI) was set up as a index to signify crown inclination in research. Ratio of crown inclination in east, west, south and north were calculated and histograms in four direction were drawn which showed that crown inclination was generally existed in research area. Principal Component Analysis (PCA) was used to measure the influence that diameter at breast height (DBH), height, height under branch and crown height had on Cunninghamia Lanceolata crown inclination. The result showed that most influential factors of the four factors were diameter at breast height (DBH) and height.
\end{abstract}

Keywords-crown inclination; cunninghamia lanceolata; analysis of influence intensity

\section{INTRODUCTION}

Crown is related to photosynthetic rate, area of photosynthesis and transmission distance of organics. Spacial distribution of factors that associated with crown, for example, branching features, number of branches, leaf area, crown length, crown surface area, crown volume etc. is the main index of depicting crown structure [1]. Crown structure has an influence on distribution of vertical trunk growth and distribution proportion of trunk growth and branch growth [2]. In addition to physiological functions, crown can be seen as an environmental factor that has a direct influence on crowns of neighboring trees and their undergrowth vegetation. Consequently. crown has an indirect influence on physiology and ecological functions, internal structure and external morphology of neighboring trees [3]. In forest communities, the amount of radiation could be directly reduced by upper canopy, meanwhile solar radiation is considered to be the key ecological factor that affects growth of undergrowth vegetation and interactions between trees and ecosystem. Therefore, crown and microclimate characteristics of undergrowth are closely related [4]. Crown extraction is gaining more and more attention in field of forest resources management, however, because of complexity of forest structure, information of crown shape and crown edges is difficult to obtain [5].

Significant temporal and spatial variability of crown shape is the result of intraspecific competition, interspecific competition, interactions and feedback regulation between trees and environment during growth[6]. Biological factors, environmental factors and morphological characteristics all have a noticeable effect on crown. Under the influence of environmental factors, to compete for light and other spatial resources, crown inclination is occurred, i.e., the crown inclines in one or several directions [7]. Biological factors that may influence crown inclination may include height, diameter at breast height (DBH), age, height under branch and so on. Most Chinese scholars focused canopy research on structuring curve of crown shape[8], analyzing influence that canopy structure had on tree growth, while few scholars researched influence that biological tree characteristics and environmental factors had on crown morphology[3].

Stand visualization improved the tree simulation that based on individual tree, provided a new access to obtain information of forest management. In current stand visualization study, crown was mainly depicted in symmetric figure such as circle and ellipse, without reflecting crown inclination. In this research, a plot of land in Huangfengqiao national forest farm, You county, Hunan Province was taken as research area and Cunninghamia Lanceolata was taken as research object. The research was aimed to provide quantized parameters for future simulation and visualization of Cunninghamia Lanceolata and to provide basic information of influence that physiological characteristics had on crown inclination for reference.

\section{METHOD}

\section{A. General Information of Research Area}

In this study, research area was located in Huangfengqiao national forest farm, you county, Hunan Province. Huangfengqiao national forest farm lies in east-west part of You county with geographical coordinates of $130^{\circ} 04^{\prime}$ $113^{\circ} 43^{\prime} \mathrm{E}$ and $27^{\circ} 06^{\prime} \sim 27^{\circ} 04^{\prime} \mathrm{N}$. Distance from east to west is about $60 \mathrm{~km}$ and distance from south to north is about $40 \mathrm{~km}$. Main geo morphology of the forest farm is low mountain in which highest elevation reaches $1270 \mathrm{~m}$ while lowest is 115 $\mathrm{m}$, and the slope is usually ranging from $20^{\circ}$ to $25^{\circ}$. The forest farm is located in humid subtropical monsoon climate region, of which average annual temperature is $17.8{ }^{\circ} \mathrm{C}$, average frost-free period is $292 \mathrm{~d}$ and average sunshine time is $1612 \mathrm{~h}$. In the region, average annual precipitation is $1410.8 \mathrm{~mm}$. April to September is the best time for trees to grow and the six months take account for $65 \%$ of annual precipitation. Forest coverage of the forest farm is $86.24 \%$ and main afforestation species are Cunninghamia Lanceolata, Pinus massoniana Lamb and Phyllostachys pubescens etc. 


\section{B. Data Acquisition}

Data was obtained in a 2013 field research of Huangfengqiao national forest farm and the basic information of plot was shown in Table 1 as follow. In the field research, every tree in the plot was measured individually. Specific methods of individual measurement were that diameter at breast height $(\mathrm{DBH})$ was measured by diameter tape with an accuracy of $0.1 \mathrm{~cm}$, height and crown height were measured by laser range finder with an accuracy of $0.1 \mathrm{~m}$, crown width in east, west, south and north was measured by diameter tape with an accuracy of $0.1 \mathrm{~cm}$ and relative coordinate was measured by total station. Specific method of site factors measurement were that elevation was measured by GPS, aspect and slope was measured by compass. At the same time, plot photos in mu ltiple angles were taken.

TABLE I. BASIC INFORMATION OFPLOT.

\begin{tabular}{|c|c|c|c|c|}
\hline Size $/ \mathrm{m}^{2}$ & Number of Trees & \multicolumn{2}{|c|}{ Mean Diameter/cm } & Age/year \\
\hline $50 \times 50$ & $\overline{230}$ & \multicolumn{2}{|c|}{20.53} & 4 \\
\hline \multicolumn{2}{|r|}{ Species } & Altitude/m & \multicolumn{2}{|c|}{ Lat itude and Longitude } \\
\hline \multicolumn{2}{|c|}{ Cunninghamia Lanceolata } & 328.48 & \multicolumn{2}{|c|}{$27^{\circ} 18^{\prime} 6^{\prime \prime} \mathrm{N}, 113^{\circ} 41^{\prime} 49^{\prime \prime} \mathrm{E}$} \\
\hline
\end{tabular}

As the research object, crown of Cunninghamia Lanceolata is generally cone, branches of Cunninghamia Lanceolata stretch outward in all directions and lateral branches are verticillate. Based on the characteristics, crown inclination of Cunninghamia Lanceolata was easy to observe which was convenient for calculation and analysis.

\section{Data Process}

Due to temporal and spatial variability of crown morphology, quantitative description of crown morphology was difficult[9]. In this paper, ratio of crown inclination (RCI) was defined as $R C I_{D}=\frac{\mathrm{W}_{D}}{\overline{\mathrm{W}}}$. In the formula, $\mathrm{W}$ represents crown width, D represents four directions namely east, west, south and north. $\bar{W}$ represents average crown width, defined as $\overline{\mathrm{W}}=\frac{\mathrm{W}_{\text {east }}+\mathrm{W}_{\text {west }}+\mathrm{W}_{\text {south }}+\mathrm{W}_{\text {north }}}{4}$. Ratio of crown inclination in east, west, south and north were represented as RCIe, RCIw, RCIs and RCIn.

Statistics of research plots data was compiled with Microsoft Excel 2010 meanwhile ratio of crown inclination was calculated. General distribution of ratio of crown inclination in four directions was analyzed with IBM SPSS Statistics 19, while principal component analys is (PCA) was used to measure influence intensity of four biological factors.

\section{RESULT AND ANALYSIS}

\section{A. Analysis of Crown Inclination}

Statistics of ratio of crown inclination(RCI) in four directions based on plot data was compiled, histograms of ratio of crown inclination(RCI) in four directions was shown in Figure 1 and Box-plot was shown in Figure 2. Maximum ratio of crown inclination in east hit 1.67 and the minimu m was 0.45 . Maximu m ratio of crown inclination in west reached 1.44 and the minimu $\mathrm{m}$ was 0.26 . Maximu $\mathrm{m}$ ratio of crown inclination in south hit 1.53 and the minimum was 0.43 . Maximum ratio of crown inclination in north was 1.58 while the minimum was 0.45. As can be seen in Figure 1, ratio of crown inclination(RCI) in four directions fell into Gaussian distribution. Average ratio of crown inclination in east, west, south and north in turn was $\pm 0.228, \pm 0.219, \pm 0.183$ and \pm 0.250 , which indicated that crown inclination was ubiquitous in the plot and crown inclination in east, west and north was relatively evident. In the four directions, crown inclination in north was most significant while it was non-significant in south. According to Figure 2, on stand scale, statistics of plot data showed that crown width in east and west were longer, in north was shorter while did not vary significantly in south overall.
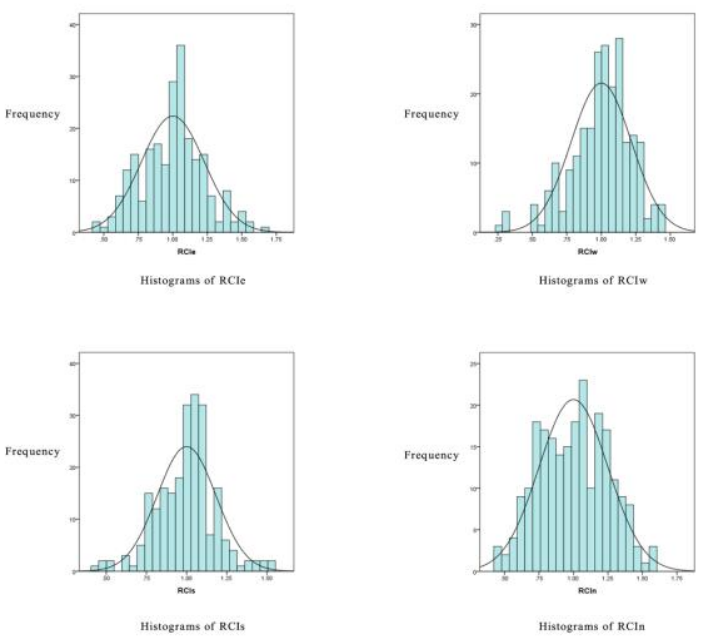

FIGURE I. HISTOGRAMS OF RCI.

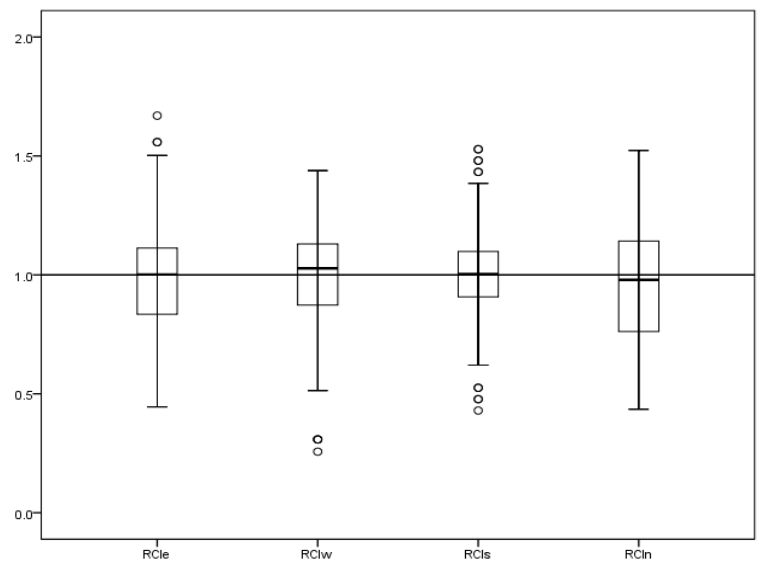

FIGURE II. BOX-PLOT OF RCI.

\section{B. Correlation Analysis of Crown Inclination and Its Influencing Factors}

By principal component analysis, the correlation coefficients of ratio of crown inclination (RCI) and its influencing factors, i.e. diameter at breast height(DBH), height, height under branch and crown height was shown as Table 2. In Table 2, total initial eigenvalue was used as the indicator of influence intensity of a principal component, which meant it showed influence intensity a factor had on crown inclination. Influence intensity of factors in descending order was diameter 
at breast height(DBH), height, height under branch and crown height. It is generally accepted that a component had a great influence if its total initial eigenvalue was greater than 1. In addition, if a total in itial eigenvalue was less than 1, it meant that influence of a component was not greater than a basic component, so the component would not be considered as principal. As is seen in Table 2, total initial eigenvalue of diameter at breast height(DBH) and height were greater than 1 and their average values were 2.476 and 1.35 , while total in itial eigenvalue of height under branch and crown height were less than 1. Consequently diameter at breast height(DBH) and height had greater correlation with crown inclination and were considered as main influencing factors, while height under branch and crown height had little influence on crown inclination so they were not counted as main influencing factors.

TABLE II. ASSOCIATION ANALYSIS OF RATIO OF CROWN INCLINATION (RCI) IN FOUR DIRECTIONS AND ITS INFLUENTIAL FACTORS.

\begin{tabular}{|c|l|c|c|}
\hline RCI & Influencing Factor & $\begin{array}{c}\text { Correlation } \\
\text { Coefficients }\end{array}$ & $\begin{array}{c}\text { Total Initial } \\
\text { Eigenvalue }\end{array}$ \\
\hline RCIe & DBH & 0.465 & 2.531 \\
\hline & Height & 0.432 & 1.338 \\
\hline & Height Under Branch & 0.168 & 0.625 \\
\hline & Crown Height & 0.123 & 0.296 \\
\hline $\begin{array}{c}\text { RCI } \\
\text { w }\end{array}$ & DBH & 0.478 & 2.480 \\
\hline & Height & 0.311 & 1.330 \\
\hline & Height Under Branch & 0.173 & 0.711 \\
\hline & Crown Height & 0.073 & 0.245 \\
\hline RCIs & DBH & 0.422 & 2.440 \\
\hline & Height & 0.277 & 1.319 \\
\hline & Height Under Branch & 0.144 & 0.752 \\
\hline & Crown Height & 0.069 & 0.251 \\
\hline RCIn & DBH & 0.487 & 2.452 \\
\hline & Height & 0.343 & 1.413 \\
\hline & Height Under Branch & 0.111 & 0.655 \\
\hline & Crown Height & -0.009 & 0.230 \\
\hline
\end{tabular}

\section{RESULT AND DISCUSSION}

Crown inclination was under collaborative influence of biological and non-biological factors and it was the result of interactions between trees and environment. In the research plot, though site conditions hardly changed, factors that influenced crown inclination was still complicated. The result showed that for most Cunninghamia Lanceolata trees, crown inclination existed on varying extent. Also, directions of inclination varied differently, crown inclination in east, west and north was manifest which meant canopy was relatively dense in west and south while canopy was sparse in east and north. Crown inclination was influenced by biological factors with different intensity and among the four biological factors that were analyzed, influence from diameter at breast height(DBH )and height was greater than from the other two.

The research showed that as biological factors, diameter at breast height $(\mathrm{DBH})$ and height had significant influence on crown inclination. Also, the research provided potential model parameters in visual simulation of crown inclination. However, competition for spatial resources among neighboring trees was left out in the research. In future researches, if the competition was considered as an influencing factor, crown inclination analys is and quantification would be improved.

\section{ACKNOWLEDGMENTS}

The paper was supported by National Natural Science Foundation of China (31170590) and National High Technology Research and Development Program 863 (2012AA102002). The paper's corresponding author is Huaiqing Zhang.

\section{REFERENCES}

[1] Liao Caixia, Estimate of crown surface area and volume. Science \& Technology Information, (16), pp. 100-101. 2010.

[2] Liu fengjue, Zheng Shikai, Lu Yongnong, Effect of tree crown disposition on the vertical distribution of annual increment in the main stem of poplar. Scientia Silvae Sinicae, 27(1), pp. 14-20, 1991.

[3] He Yaping, Fei Shimin, Xu Jia, Crown inclination of Pincus yunnanensis gap border trees and the influencing factors in the mountain area of southwest of Sichuan, southwestern China. Journal of Beijing Forestry University, 29(6), pp. 66-71, 2008.

[4] Zhang lei, Yu Haiye, Yang Haoyu, Theoretical research on a model for predicting the shadow boundary of an individual conical crown on a slope. Acta Ecologica Sinica, 26(10), pp. 3317-3323, 2006.

[5] Fu Yao, Wang Xinjie, Sun Yujin, A study of tree crown information extraction method. World Forestry Research, 26(004), pp. 38-42, 2013.

[6] RandyL. Roeh, Douglas A. Maguire, Crown profile models Based on branch attributes in coastal Douglas - fir. Forest Ecology and Management, 96(1-2), pp. 77-100, 1997.

[7] Xian Junren, Hu Tingxing, Wang Kaiyun, Studies on the characteristics of gap bordertrees in the subalpine coniferous forest in western Sichuan. Forest Research,17(5), pp. 636-640, 2004.

[8] Lei Bo, Zhang Gen, Liu Shengxiang, Liu Xia, Xi Rong, Wang Xu, Difference and cause analysis of crown shape of three tree species in different site conditions of Jinsha River Region. Forest Inventory and Planning, (2), 2012.

[9] Pearcy R W, Ehleringer J R, Mooney H A, et al, Plant physiological ecology: field methods and instrumentation, Chapman and Hall Ltd, 1989. 